\title{
Os Programas de Emagrecimento na Internet: um Estudo Exploratório
}

LIGIA AMPARO DA SILVA SANTOS •

Este texto é parte de um estudo sobre estratégias educativas utilizadas pelos programas de emagrecimento oferecidos via Internet e tem como objetivo descrever e analisar alguns elementos estruturantes desses sites. Observouse que os mesmos utilizam estratégias que se aproximam mais da realidade cotidiana dos participantes, e que aspectos psicológicos e motivacionais são considerados importantes. Além disso, há uma tentativa de criar estratégias educacionais que transitem da concepção do "fazer dieta" para o conceito de reeducação alimentar concebida como "o comer de tudo, sem passar fome". Tal fato revela uma aliança entre as ciências da nutrição e a gastronomia, que representa um elo importante nas tentativas do resgate do prazer em comer. Destaca-se a importância de estudar tais estratégias, uma vez que o emagrecimento tem sido uma meta desejada por grande parte da população, seja com objetivo de ampliar a qualidade da saúde, seja com fins estéticos.

Palavras-chave: dieta; programa de emagrecimento; nutrição; Internet.

Recebido em: 01/08/2006.

Aprovado em: 14/09/2006. 


\section{A história de Ademaria}

O site "Emagrecendo" exibia um filme que conta uma história, baseada em fatos reais, sobre uma mulher obesa chamada Ademaria. Ela já havia feito várias dietas sem muito sucesso, até encontrar a chamada "dieta dos pontos", elaborada pelo Doutor Alfred Halpern. A primeira cena da história é o Doutor Halpern se apresentando e dizendo: "Durante toda a minha vida já vi muita gente fazendo tudo para emagrecer". Em seguida, ele apresenta a personagem Ademaria, que perdeu 28 quilos com ajuda do programa de emagrecimento promovido pelo site. Aparece uma série de imagens na qual a personagem reflete sobre si mesma, dirigindo-se para quem está assistindo o filme, ou se olhando no espelho:

Faço tudo, mas as dietas não funcionam enquanto estou me restringindo, me castigando com sopas, saladas e grelhados. Estou cansada de soluções prontas e proibições, ninguém se preocupa com as coisas que eu gosto de comer. Faço regime, passo vontade e até emagreço, mas ninguém agüenta isso para sempre! Eu acabo engordando de novo. Eu me sinto culpada, frustrada, um fracasso!!! Será que vou ficar assim a vida toda?

Em seguida entra o médico, Dr. Halpern, tecendo seus comentários:

Se você faz restrição acaba exagerando e fica triste. Cortar carboidratos, proibir doces e outras coisas gostosas, além de incoerente, é uma crueldade. O sistema de pontos é como um curso no qual você vai aprendendo o quanto comer de cada alimento, funciona há 30 anos e nenhum alimento é proibido.

A personagem pergunta: "Como posso comer de tudo, chocolate e tudo mais, e ainda assim emagrecer? Só se for milagre!!”. O médico aparece com as asas de anjo que se desmancham no ar: "Não é milagre e vai depender de você também. Vamos ensinar você a emagrecer e continuar magra". As personagens mantêm o diálogo:

A - Todo mundo me fala que preciso fazer reeducação alimentar. É isso que você está falando Doutor Alfred?

Dr. - É exatamente isso! O sistema de pontos funciona como um curso.

A - Sozinha eu não vou conseguir! 
Dr. - Você nunca estará sozinha. Nossa equipe de monitoras estará ao seu lado para ensinar. Elas vão mostrar como contar os pontos, dar apoio para contornar dificuldades. É esse acompanhamento que faz diferença.

A - É verdade, doutor. A vida já está cheia de limites e comer é tão bom! Mas quem disse que eu agüento comer só um pedacinho de chocolate? Eu perco o controle!

Dr - Aprender a controlar essas situações faz parte do aprendizado. Você vai calcular os pontos de acordo com o seu peso, altura, idade, hábitos alimentares e atividade física.

A - Vou fazer!

Meses depois, a personagem reaparece - trocando as roupas escuras por roupas claras - comentando:

Anoto tudo que como, conto os pontos e os lanço no site Emagrecendo. Encaro isso com um curso mesmo. Toda a semana me peso e faço a minha avaliação pela Internet. Com a tabela aprendi a pontuação. Mesmo quando exagero, conto os pontos. As monitoras podem me explicar como contornar as dificuldades, reforçando meu aprendizado. Eu uso telefone, e-mail, chat, quantas vezes eu quiser [...] Agora eu sou outra pessoa de bem com a vida. Agora adoro o espelho. Espero que você descubra como é bom sentir-se bem com o seu corpo. Emagrecer sem abrir mão do que gosta de comer...

Ao final aparecem fotos da mulher, antes e depois de ter participado do programa, cuja história real foi a base do filme.

Essa história parece ilustrar uma mudança na concepção de dieta alimentar que tem como base as críticas em relação às dietas tradicionais, considerando-as rígidas, monótonas e pouco efetivas. Traz um novo conceito: a reeducação alimentar. Como o filme mostra, a reeducação alimentar preconiza a flexibilidade, a possibilidade de comer tudo que gosta, não abrindo mão do prazer e não voltando a engordar. Emagrecer, de acordo com o filme, é resultado de uma aprendizagem que depende do próprio indivíduo, a aprendizagem do quanto comer e principalmente a do autocontrole.

O presente texto procura descrever e analisar algumas estratégias utilizadas pelos programas de emagrecimento oferecidos pela Internet, buscando 
ainda focar os novos parâmetros que estão sendo construídos em relação aos regimes alimentares. Para tanto, o texto fará inicialmente algumas breves considerações sobre o corpo e o comer na modernidade; em seguida, um percurso pelo mundo da dieta na Internet, chegando a uma leitura sobre os sites dos programas de emagrecimento veiculados no Brasil; por último, algumas considerações finais.

\section{Breves considerações sobre o corpo e o comer na modernidade}

O fenômeno do culto ao corpo na modernidade tem sido uma temática instigante para as Ciências Sociais nos últimos anos. Diferentes autores discutem os sentidos do corpo no mundo contemporâneo, relacionando-o com os valores atuais, tais como Anthony Giddens, Christopher Lasch, Richard Sennett, Zygmunt Bauman, Gilles Lipovetsky, dentre outros. Longe de partilharem as mesmas posições sobre o tema, pode-se afirmar que os autores convergem na idéia do corpo enquanto um objeto privilegiado da reflexão sobre a vida social e a condição humana no mundo contemporâneo. Compartilham também da discussão do corpo como algo em construção permanente do próprio ser (SANTOS, 2006).

O ideário do corpo esbelto e as práticas corporais prescritas para o suposto alcance do corpo idealizado, como também sua estreita relação com a tríade beleza, juventude e saúde, são dimensões imbricadas convergindo para um complexo único que caracteriza a construção do corpo moderno. A noção de um corpo construído, não distinto do self, marca as recentes elaborações sobre o tema. Giddens $(2001$, p. 92) define o corpo não apenas como uma entidade que nós possuímos, "é um sistema ação, um modo de práxis, e a sua imersão prática nas interações da vida do dia-a-dia é uma parte essencial da manutenção de um sentido coerente de auto-identidade". Aparência e essência se confundem, interagem e são campos de agenciamento contínuo para sua permanente construção.

Nesse processo, a cultura do corpo, segundo Lipovetsky (2000), tornase técnica e voluntarista; quanto mais se impõe o ideal de autonomia individual, mais aumenta a conformidade aos modelos sociais do corpo. A cultura da eficácia e do controle técnico são elementos característicos dos tempos modernos. O corpo torna-se um objeto que merece trabalho constante de si sobre si, parecendo constituir uma "correção da obra da natureza". 
Dentre as estratégias utilizadas para a busca do corpo magro-jovembelo, a atividade física e o regime alimentar são dois pilares fundamentais deste processo. Com a participação dos avanços dos conhecimentos científicos e tecnológicos nestes respectivos campos, a intervenção humana vem-se aprimorando e emergem inúmeras possibilidades de ação sobre o corpo. A prescrição dessas práticas engloba uma rotinização e, cada vez mais, uma interdependência para a suposta conquista do corpo ideal. Os regimes corporais são práticas aprendidas que acarretam um controle contínuo do corpo e de suas necessidades orgânicas. Os regimes são, afirma Giddens (2001), de importância central para a auto-identidade, precisamente porque ligam os hábitos a aspectos da aparência visível em si, e que afetam a forma do corpo. Desta maneira, pode-se supor que a imagem corporal é um espelho do self.

Há evidências de que emagrecer é um imperativo central na vida de muitos indivíduos cuja motivação principal pode ser de ordem estética, e esta ainda pode entrar em conflito com a motivação oriunda da ordem médica. Os métodos de emagrecimento têm sido questionados. Há um verdadeiro exército industrial a serviço do emagrecimento, com seus chás, shakes, pílulas, programas, receitas e dietas que prometem milagrosos resultados como, por exemplo: "Emagreça sete quilos em duas semanas".

Os temas da alimentação e da dieta estão presentes em todos os meios de comunicação, assim como os anúncios e propagandas de diversos tipos de produtos alimentares. Alimentos orgânicos, naturais, integrais, funcionais, light, fast food, alimentos com a manipulação dos componentes nutricionais carboidratos, proteínas, gorduras, colesterol, fibras, sal, açúcar - e os componentes que fazem parte da sua produção e processamento - com aditivos, contaminação biológica, pesticidas, hormônios e antibióticos, as modificações genéticas dos polêmicos alimentos transgênicos, dieta mediterrânea e as infinitas pesquisas sobre os benefícios e malefícios da dieta para a saúde, dentre múltiplos outros termos e temas, constituem um complexo de informações que percorrem o imaginário coletivo de uma população diversificada.

Trata-se de uma sociedade hiperinformada através de múltiplos discursos: publicitário, médico-nutricional, hedonista, progresso e modernidade, exótico e da diferença (ARNAIZ, 1996; FISCHLER, 2001). Discursos muitas vezes convergentes, mas por vezes conflitantes. Essa população está em contato com estas informações, assumindo múltiplos papéis, como também classifica 
Arnaiz (1996): consumidores, leitores, pacientes, telespectadores, cidadãos, alunos e, incluindo na sua lista, internautas.

Dentre a diversidade de discursos aliados a uma diversidade de produtos que a indústria de alimentos tem proporcionado à sociedade, emerge um conjunto de opções, e cabe a cada indivíduo, paradoxalmente, uma única alternativa: a escolha. Giddens (2001) aponta a escolha como o componente fundamental da atividade cotidiana no terreno existencial da modernidade tardia. É exatamente a complexa diversidade dessa modernidade que marca tal escolha, tendo ainda o pouco auxílio para selecionar as opções. A pluralidade dos estilos de vida é apontada como um dos traços que marcam a experiência da modernidade. Trata-se de práticas rotinizadas que se incorporam em hábitos de vestir, comer, modos de agir, abertas às mudanças que envolvem as múltiplas decisões diárias. Essas decisões não são apenas do como agir, mas também sobre quem deseja ser.

Dentro deste universo, a Internet é um espaço importante que se constituiu nas últimas décadas, difusor tanto de um discurso midiático em torno do corpo idealizado como de um discurso publicitário inserido na lógica de um mercado voltado para o emagrecimento. No campo dos programas de emagrecimento, um dos sites pioneiros foi o "Weight Watchers", que já trabalhava com publicações no ramo. O site "Ediets.com" é o líder nesse mercado atualmente, com cerca de 11 milhões de cadastrados. No Brasil, na última década, começaram a surgir sites que vendem esses serviços e que estão sendo bastante utilizados por uma parcela da população.

\section{O percurso metodológico}

Tratou-se de um estudo exploratório com o propósito de explicitar alguns aspectos do fenômeno em foco: as estratégias utilizadas pelos programas de emagrecimento veiculados na Internet. A primeira etapa foi explorar um site de busca, utilizando como palavra-chave o termo "dieta". O site de busca escolhido foi o "Yahoo.com.br", por ser considerado um dos sites mais explorados pelos internautas no período estudado. Na primeira busca, realizada no período de 8 a 11 de julho de 2003, foram localizados 336 sites cadastrados e 74.800 sites relacionados, englobando uma grande variação de abordagem da temática.

O estudo se concentrou nos 336 sites cadastrados, selecionando-se aqueles que estavam relacionados com os programas de emagrecimento comercializados no Brasil. Dentre eles, foram escolhidos seis sites utilizando- 
se o critério de popularidade no contexto nacional, além da abrangência das temáticas exploradas pelos programas.

Foi realizada análise dos conteúdos veiculados do material selecionado: o primeiro momento envolveu uma leitura exploratória do material; em seguida, desenvolveu-se um processo de categorização dos temas relevantes para análise, realizando-se ainda uma triangulação de dados.

Os sites também foram acompanhados semanalmente durante dois meses, para verificar as permanências e as dinâmicas dos fluxos de informações e conteúdos dos programas.

\section{O mundo da dieta na Internet}

Nos sites cadastrados, a dieta estava presente nas mais variadas temáticas e propósitos: sites de dietas tradicionais já popularmente conhecidas, como a dieta da Lua, dieta das proteínas; oferta de programas de dietas balanceadas ou específicas para promover o emagrecimento, dietas para patologias específicas, como diabetes e doenças coronarianas; sites de dicas em geral sobre dieta; sites de receitas light, tabelas de calorias, matérias correlacionadas e depoimentos em alguns sites pessoais; spas; simpatias; informações sobre temas como os perigos das dietas rigorosas, bulimia e anorexia; psicologia comportamental relacionada com dieta e obesidade; atividade física em geral esportes - fisiculturismo - e academias; cirurgias para obesidade mórbida; transtornos alimentares; software para avaliação nutricional; grupos terapêuticos de emagrecimento; da Associação Brasileira dos Gordinhos; venda de produtos como refeições congeladas, produtos naturais, dietéticos e fitoterápicos para emagrecer; kits-emagrecimento; como também sites contrários ao movimento de culto ao corpo, e inúmeros outros.

Neste breve olhar, como já era esperado, a associação da dieta à moda, beleza e saúde é bastante freqüente. Contudo, não menos freqüente, encontrase a associação com as práticas consideradas alternativas: medicina alternativa, esoterismo e misticismo. As tradicionais simpatias para emagrecer também não deixam de participar:

Quarta-feira pela manhã, coloque meio copo de água e dentro dele o número de grãos de arroz correspondente aos quilos que você deseja perder, não coloque grãos a mais do que deseja, pois os quilos perdidos não são 
recuperados. À noite beba a água, deixando os grãos de arroz e completando novamente com meio copo de água. Quinta-feira pela manhã em jejum, beba a água deixando os grãos de arroz e completando com meio copo de água. Na sexta-feira pela manhã, em jejum, beba a água (e desta vez com os grãos de arroz junto).

Partindo da tradicional simpatia, passando pelas práticas esotéricas mais elitizadas, chegando à intermediação da ciência, estes sistemas de referências são constantemente utilizados como instrumento norteador das orientações alimentares, seja para manutenção da saúde e/ou beleza, seja na busca do corpo magro e/ou musculoso. Percebe-se que a questão da disciplina alimentar penetra nos mais amplos espaços sociais, assumindo cada vez mais relevância.

Dentro desses múltiplos universos, busca-se uma identidade particular da dieta, de acordo com os mais variados estilos de vida. Pode-se optar por uma dieta rigorosa, com mensagens do tipo "Perca $4 \mathrm{~kg}$ em uma semana!" na busca do corpo perfeito; ou "Emagreça sem dieta", centrando na dieta balanceada e harmônica, buscando uma "conscientização corporal"; ou ainda as dietas voltadas para o ganho de massa muscular, buscando o delineamento das formas corporais. Contudo, há indicativos de que, apesar dessas diversificações, a centralidade na dieta hipocalórica e hipolipídica perpassa todas as opções e estilos de vida, tendo em comum que advêm do campo científico.

Por outro lado, todo este movimento não ocorre sem advertências e até resistências. Sites como o da Associação Brasileira dos Gordinhos, o do movimento Slow Food e algumas mensagens do site da Associação Brasileira para o Estudo da Obesidade (Abeso) demonstram esse aspecto. A Abeso, uma sociedade multidisciplinar voltada para desenvolver e disseminar o conhecimento no campo da obesidade e promover contatos, traz mensagens rigorosamente contrárias ao movimento das dietas rigorosas, como expressa fortemente esta: "A tirania da moda nos faz acreditar que a esbeltez é sinônimo de beleza e nos torna escravos do culto ao corpo, a qualquer preço. Não venda o seu corpo e a sua saúde ao diabo!"

A Associação Brasileira dos Gordinhos, que tem um site experimental, busca congregar os obesos, promovendo uma melhoria da auto-estima. Referem-se aos "gordinhos felizes e satisfeitos" com seus corpos, discutem o conceito de beleza vinculado à magreza e assumem que emagrecer não é uma necessidade ou obrigação. No entanto, para os que desejem ou realmente 
necessitem - supondo-se problemas de saúde - o site oferece auxílio sobre os caminhos para o emagrecimento.

Slow food é uma associação italiana fundada em Paris, em 1989, cuja principal mensagem é ser "um movimento de proteção do direito ao sabor". A associação possui 70 mil associados em 48 países. Desenvolve workshops, cursos, livros e publicações voltadas para a educação do gosto, assim como ações de educação em colaboração com professores nas escolas infantis. Procura ensinar o uso dos sentidos e convencê-los da importância dos produtos alimentares para a cultura da sociedade. Vinculados a esta importância, a Associação possui projetos que ajudam a assegurar a biodiversidade. O projeto The Ark of Taste objetiva catalogar produtos, pratos e animais, que estão denominando de ecogastronomia. Isso reflete a dupla face da globalização, que se de um lado, tem resultado numa espécie de mundialização do gosto, de outro, tem efeito reverso: o movimento de retorno e preservação das culturas alimentares regionais, na busca da preservação da identidade alimentar.

Dentro do quase infinito universo da Internet, há uma variedade muito maior de sites que não foram englobados aqui - como, por exemplo, movimentos radicais a favor das portadoras de anorexia. De certa forma, tal exploração foge ao propósito central deste texto, que é centrar no sites que oferecem programas de emagrecimento.

\section{Uma leitura sobre os sites de programas de emagrecimento no Brasil}

A Associação Paulista de Nutrição (APAN) tem realizado debates, também localizados na Internet, sobre os sites que fornecem programas de dietas, situando posições contrárias e a favor desses programas. Não se pode negar que, se ainda não for, trata-se de uma fatia potencial no mercado da Internet em termos de dieta, ao lado da venda de produtos alimentares relacionados com o emagrecimento.

A Internet é um caso exemplar que mostra uma das características da modernidade apontada por Giddens (2001): as modificações do espaço e do tempo. No caso dos programas de dieta, os quais o usuário pode acessar a qualquer hora e de qualquer lugar, transpõe barreiras geográficas, com rapidez e dinamicidade, aspectos citados como algumas das vantagens que esses tipos de programa apresentam. 
Trazendo um panorama descritivo genérico, os sites estudados, ${ }^{1}$ para efeito de análise, podem ser divididos em duas partes principais: os conteúdos abertos, de domínio público, e os conteúdos fechados, só para os assinantes dos programas.

\section{Os conteúdos abertos}

Em relação aos conteúdos abertos, pode-se elencar os seguintes elementos estruturantes presentes nos sites: imagens, receitas, matérias e reportagens, depoimentos e outros. Trataremos destes elementos a seguir.

\section{As imagens}

Estão presentes nos sites imagens de pessoas de diferentes características: sejam personalidades famosas com seus depoimentos e dicas para manter a forma ou de como resistir à "tentação" da comida, sejam pessoas comuns que utilizam ou utilizaram o programa e obtiveram sucesso, ou ainda de pessoas em boa forma, como estratégia de marketing.

O primeiro grupo vale-se de uma estratégia já bastante utilizada nas revistas femininas, como ressalta Mira (2002), em que personalidades funcionam como identificação e projeção, servindo como estímulo ao público. Contudo, não se observou exploração das imagens do corpo das personalidades, como se observa nas referidas revistas. Centra-se mais no seu depoimento sobre como mantêm a boa forma, relatos de suas experiências com o emagrecimento e outras dicas.

O segundo grupo constitui a estratégia do "antes e depois", que é bastante comum, como demonstrativo dos resultados concretos do programa. Castro (2003) identifica tal estratégia quando estuda as revistas femininas, destacando que o recurso das redatoras é colocar "gente como a gente", o que traz maior identificação com o público. Tal argumento serve para a elaboração dos programas. Com as tecnologias da informática, muitos sites sobrepõem as fotos, alternando as imagens do antes e depois do emagrecimento, fazendo um jogo visual que pode causar importante impacto nos potenciais usuários.

Por fim, o terceiro grupo: sempre estão presentes nas aberturas dos sites. Geralmente são mulheres, raramente famosas, vestidas com roupas esportivas que permitem delinear suas formas físicas, em situações de atividade física, seja na academia, seja próximo à natureza - na praia, por exemplo -, na qual sempre traz a idéia de movimento e leveza. Elas estão freqüentemente 
correndo, caminhando ou se alongando. Suas expressões trazem a mensagem de "estar de bem com a vida" ou "de bem consigo mesma". A região do corpo mais focada é o abdômen. A eliminação do tecido adiposo da região abdominal é um aspecto bastante simbólico da forma física da mulher moderna (SANTOS, 2006). Aparecem também fazendo refeições em lugares confortáveis, com comidas "leves", "coloridas" e "saudáveis". As roupas que vestem expressam leveza. Quase sempre são claras, combinando com o estilo light.

O termo light, ressalta Freitas (2002, p. 24), na sociedade atual significa um modo de vida leve e saudável que também pode ser reinterpretado como "o sentido da leveza da mesa, dos alimentos, do corpo e da vida". Destaca ainda que dessa leveza se decifra o mundo light e clean, vinculado à idéia de um corpo magro e limpo, adjetivos de um novo corpo combinando com a forma leve e iluminada. As roupas claras parecem assumir também tal significação. Leva-se em conta que, como ainda lembra a autora supracitada, o termo light na língua inglesa pode significar tanto leveza como iluminação ou claridade. Atualmente, o termo light não se restringe apenas aos produtos alimentares, mas se difundiu para os estilos de vida nos quais a leveza é a marca.

Também são freqüentes as imagens das balanças e fitas métricas, instrumentais considerados fundamentais para o controle, registro e vigilância do processo, representando o grau de tecnificação dos instrumentos de controle no processo de emagrecimento.

\section{As receitas}

Inúmeras receitas e dicas culinárias são oferecidas, utilizando uma diversidade de produtos alimentares light. O uso técnico-científico nos diferentes pontos da cadeia de produção alimentar - melhoramento genético e o uso de fertilizantes na produção dos gêneros alimentícios, melhoria no transporte e acondicionamento, com as tecnologias de conservação que aumenta o tempo de vida útil dos alimentos, a expansão das complexas redes de supermercados, como as tecnologias domésticas (microondas, freezer, etc.) contribuíram para facilitar, ampliar e diversificar a oferta de alimentos (POULAIN, 2003). Há, como aponta Giddens (2001), uma desterritorialização do alimento na modernidade, gerada pela grande oferta mundial das mais diversas procedências. O mundo global transpassa as barreiras do espaço e do tempo, e pode caber numa única mesa sob a forma das inúmeras possibilidades culinárias. 
Por outro lado, as receitas também são importantes num período no qual se identifica com a ruptura do saber-fazer alimentar no mundo contemporâneo. O livro de receitas, invenção do século XVIII, foi o início das mudanças nas formas habituais de comunicar os conhecimentos alimentares cotidianos, como destaca Arnaiz (1996): a transmissão oral feminina, principalmente entre mães e filhas.

A presença das receitas nesses sites indica haver uma aproximação entre a gastronomia e as ciências da Nutrição. Lupton (1996) resgata a emergência das ciências nutricionais, que têm sua história construída em paralelo com a da gastronomia. Enquanto a gastronomia e a haute cuisine estavam se desenvolvendo na França, nos Estados Unidos e na Inglaterra do século XVIII, estavam surgindo as ciências nutricionais e os regimes dietéticos voltados à restrição do comer, para fins de alcançar a boa saúde.

Turner (1982) discorre sobre os escritos de George Cheyne publicados entre 1724 e 1742, que adotava uma metáfora mecânica do corpo para discutir a importância dos regimes alimentares. Os problemas nutricionais e de saúde que afetavam a Europa nos meados do século XIX, particularmente das classes trabalhadoras, estimularam o avanço desse campo científico. Nesse período, os cientistas britânicos separaram os alimentos em partes constituintes: proteínas, carboidratos, lipídios, minerais e água, descobrindo a função de cada um deles no organismo. Iniciou-se também a diferenciação das dietas para cada grupo específico, baseado nas divisões de gênero, idade e ocupação, centrando-se ainda na necessidade energética de cada um destes grupos. A noção de "dieta ideal" começou a emergir.

Já nos Estados Unidos, no período de 1900 a 1930, surge o movimento "new nutrition", que tinha como base as recomendações para a seleção dos alimentos baseados na sua composição química no lugar da sua aparência e sabor. Fischler (2003) relembra que, no bojo desse movimento, os "reformadores americanos", em nome da ciência, tentaram intervir na dieta dos imigrantes italianos, que até então era considerada "insuficiente, grosseira e carente". A imagem da cozinha italiana só foi invertida, de forma progressiva, após a Segunda Guerra Mundial, surgindo como modelo de frugalidade e, após, como um modelo gastronômico.

Lupton (1996) também destaca as três maiores fases das ciências nutricionais no mundo britânico no século XX: a primeira foi a descoberta dos micronutrientes essenciais, dentro das pesquisas sobre a prevenção das 
deficiências nutricionais; a segunda fase foi após a Segunda Guerra Mundial, concentrada na produção de alimentos; e a terceira emergiu nos anos 1970, com ênfase no papel da dieta nas doenças crônicas em adultos.

Aqui é ressaltado o papel das vitaminas, que foram individualmente isoladas e denominadas. Nesse período, sua importância era voltada para prevenção e recuperação das carências nutricionais, estimulando o consumo de alimentos ricos desses nutrientes. Primeiramente, ovos, leite, manteiga, e folhosos, devido ao conteúdo de vitamina A; em seguida, outros produtos, fontes de outros minerais e vitaminas como vísceras, peixes, frutas e vegetais. Atualmente, não anulando este papel das vitaminas e minerais nas deficiências nutricionais, principalmente nos países subdesenvolvidos, as pesquisas apontam os vínculos de certas vitaminas e minerais na prevenção das doenças crônico-degenerativas.

Deve-se também considerar que tudo isso movimentou a indústria de medicamentos, com os complexos vitamínicos, assim como a indústria de alimentos enriquecidos. A indústria de alimentos foi um dos alvos desse processo, em que os profissionais propuseram alimentos "naturais" no lugar dos alimentos processados e refinados. Frutas e verduras, até então consideradas supérfluas, passaram a ser consideradas vitais à saúde.

Lupton (1996) afirma que a história da ciência da nutrição demonstra um aumento da tendência à racionalização, vigilância e regulação da dieta das massas, com base nos avanços científicos. Os discursos da produção e da metáfora econômica e mecânica dominaram as ciências nutricionais com estudos direcionados para determinar como o corpo humano converte o alimento em energia. Não apenas a dieta é construída para o bem-estar, como se tornou uma questão para a regulação estatal; como os corpos se tornaram reconhecidos como máquinas produtivas, vital para os interesses econômicos e militares do Estado.

Contudo, mudanças drásticas nos hábitos alimentares ocidentais ocorrem a partir da metade do século XX. A lipofobia domina os Estados Unidos e o mundo torna-se contrário aos leites e derivados tão louvados em tempos anteriores. Lupton (1996) indica a queda do consumo desses produtos nos EUA, e Lipovetsky (2000) demonstra dados sobre o crescimento da produção dos produtos diet e light nos EUA. A queda do consumo de gorduras nos EUA é brusca; no entanto, o problema da obesidade continua em ascensão, fator que preocupa significativamente os profissionais e pesquisadores deste campo do saber. 
Enquanto isso, a gastronomia, invenção francesa do século XVIII, segue seu curso até a descoberta - ou a invenção de nutricionistas americanos, em particular - da chamada dieta mediterrânea. Nos anos 1990, a publicação do artigo "Paradoxe français" inicia um processo de revolução que abala as estruturas científicas nas quais se apóiam as ciências nutricionais. De todos os países desenvolvidos, a França é, depois do Japão, onde se morre menos de doenças cardiovasculares, apesar de toda sua reputação gastronômica. Os franceses consomem quase tanta gordura quanto os americanos, os britânicos e os europeus do Norte, e apresentam níveis de colesterol similares aos deles (FISCHLER, 2002).

A ciência se volta para o mundo mediterrâneo, tentando desvendar o "segredo" que o envolve no que tange a suas práticas alimentares. Enquanto isso, a indústria dos produtos do mediterrâneo - óleos de oliva, vinhos, dentre outros - tem tido um incremento importante com este status de possuidora de ingredientes da "dieta ideal". Pode-se recordar que a cozinha italiana, considerada nos EUA até a Primeira Guerra Mundial como um modelo de frugalidade, conforme aludido anteriormente, passou a ser considerada como modelo gastronômico apreciado por todo o mundo, e passa agora para o status de uma dieta saudável e protetora da saúde.

No Brasil, os nutricionistas, cuja formação tem forte influência americana, sempre procuraram se distinguir da gastronomia proclamando "fazer ciência". Nos finais dos anos 1970, o termo "culinária" estava presente nos títulos de algumas disciplinas dos cursos de graduação em Nutrição, como Técnica Culinária ou algo similar. Estas foram permutadas para a Dietética termo considerado mais científico - como Técnica Dietética, Nutrição e Dietética. Atualmente, a gastronomia integra-se aos currículos como uma área de conhecimento importante.

Eis alguns traços em que as linhas do horizonte das ciências nutricionais e a gastronomia começam a se cruzar nos finais do século XX. A gastronomia está relacionada com a criatividade e invenção, contrária à monotonia e resistência às dietas tradicionais. A gastronomia aparece no cenário como uma tentativa de recuperar a dimensão do prazer nas práticas alimentares. Desta forma, os sites de emagrecimento exploram esse campo, oferecendo suas possibilidades culinárias do que se tem convencionado a chamar de cozinha light, destinada à construção do corpo light. 


\section{Matérias, reportagens e depoimentos}

Há muitos textos, matérias, reportagens e dicas sobre diferentes temas: a) alimentos, suas propriedades nutricionais e nutracêuticas prioritariamente, novidades científicas sobre os mesmos; b) alimentação e dieta em si, dicas do como comer fora (no trabalho ou nos restaurantes), dicas do que fazer quando sentir fome; c) atividade física, modalidades esportivas, dicas de como desenvolver estas atividades, quantidade calóricas que são gastas, etc.; d) moda e beleza, novidades em produtos e intervenções médico-cirúrgicas; e) temas de cunho psicológico e motivacionais, voltados para oferecer um suporte àqueles que estão buscando fundamentalmente perder peso, como temas sobre o bemestar, auto-estima, estímulos e motivações "para vencer", dentre outros.

Quanto aos depoimentos, estes tratam de histórias bem-sucedidas, pessoas que resolveram por algum motivo mudar de vida, ou que têm ao longo do tempo se confrontado com o peso, destacando inúmeras tentativas com diferentes dietas sem sucesso. O sucesso é traduzido em conseguir emagrecer e mudar hábitos alimentares sem sofrimento, não abrindo mão do que se gosta de comer. Por consequiência, sentem-se estar de "bem com a vida' e/ou "de bem com o corpo", ou ainda "consigo mesma" (mensagens bastante recorrentes), ter aumentado a auto-estima, melhorado a vida, os relacionamentos. São pessoas de todo o país, e de todos os sexos, com suas histórias particulares.

Dentre outros aspectos presentes nos sites, o cálculo do índice de massa corporal (IMC) é um dos primeiros elementos que se visualiza nas páginas. Trata-se de um espaço no qual o sujeito registra seu peso e altura, que será calculado e indicará seu estado nutricional. Também se encontra a tabela de calorias, informando o valor calórico dos alimentos. São dois aspectos importantes no monitoramento e controle do projeto de emagrecimento.

\section{Os conteúdos fechados}

Em relação aos conteúdos fechados, os sites oferecem espaços para compras de produtos, livros, dentre outros; a visualização do progresso da dieta, os diários, a calculadora dos pontos e o plano alimentar.

Quanto ao funcionamento, os programas apresentam muitas similitudes. Em termos gerais, as pessoas fazem a inscrição e têm um canal exclusivo de $e$ mail, além do chat e telefone - com horários preestabelecidos; incluem-se também horários específicos para os finais de semana. Os usuários podem 
criar uma identificação, que pode ser o próprio nome ou um apelido. O cliente cria uma senha para acessar o programa com todo sigilo, garantindo a confidencialidade e privacidade do usuário.

Em seguida, os interessados lançam uma série de informações sobre peso, altura, idade, atividade física, preferências alimentares, o quanto desejam emagrecer, dentre outras, que irão nortear as orientações oferecidas. Após a avaliação inicial, as pessoas recebem sua prescrição periodicamente e devem preencher um diário com informações que irão auxiliar nos redirecionamentos, quando necessário. Embora considerem as individualidades e cada pessoa pode reagir de uma forma, a meta em geral é emagrecer até $4 \mathrm{~kg}$ por mês, trabalhando com dietas com cerca de 1.200 calorias divididas em seis refeições.

As quantidades calóricas podem ser reajustadas caso as pessoas cometam "deslizes" - palavra muito utilizada em diferentes sites. Os deslizes são permitidos e considerados normais, pois existem os desejos, os eventos sociais, dentre outros. O essencial é que a pessoa faça uma "correção" num próximo momento.

A prescrição vai desde a dieta mais tradicional, baseada nas alíquotas de nutrientes e construção dos cardápios que oferecem opções, até a dieta dos pontos ou das cotas. Nestas são atribuídos pontos aos diferentes alimentos com seus específicos porcionamentos, no qual o indivíduo tem uma quantidade preestabelecida. Sua tarefa será quantificar diariamente tudo o que ingere, preenchendo na Internet e calculando os pontos. Os programas monitoram o progresso da pessoa, realizando avaliações nutricionais através do peso e da altura, em média uma vez por semana.

Uma tríade de especialistas fica à disposição dos usuários: especialistas em nutrição, atividade física e psicologia. As mensagens, assim como os depoimentos, atribuem permanentemente uma situação de conforto e apoio, através desses profissionais: "Imagine uma equipe inteira só para você, ao seu lado!". Trata-se de uma relação paradoxal, na qual, ao mesmo tempo, você não conhece quem está controlando e auxiliando no seu processo, mas sabe que está constantemente presente "ao seu lado", "a qualquer hora".

Com a modernidade, que conta com o aparato tecnológico da Internet, tem-se, de um lado, a confidencialidade e o anonimato, com um apelido através do qual a relação se estabelece entre dois pólos que não se conhecem, que podem se situar em pólos geográficos bem distantes. Por outro, tem-se uma relação que pode se estabelecer em diferentes horários - mais do que numa 
relação médico-paciente - por vários mecanismos, com conforto e segurança. Uma distância e um anonimato que, ao mesmo tempo, demonstram uma suposta proximidade e relação afetiva.

\section{Considerações finais}

O propósito deste artigo foi descrever e analisar as estratégias utilizadas por sites de emagrecimento oferecidos pela Internet. Trata de um estudo exploratório que gerou mais questões para refletir, indicando muitas possibilidades de leituras e interpretações desses sites.

Uma questão fundamental, ainda que fora do escopo deste trabalho, se refere às razões que levariam os sujeitos a participar de um programa de emagrecimento na Internet em lugar de buscar um profissional de saúde. Este fato faz refletir sobre o papel da Internet na vida cotidiana dos sujeitos sociais. Seria necessário compreender melhor tal fenômeno, incluindo o debate em torno da existência ou não de um dualismo entre a realidade e virtualidade, se o mesmo constitui espaço virtual fora da realidade ou é parte do mesmo, os impactos sobre a construção de novas subjetividades, dentre inúmeras outras questões discutidas por diferentes autores (LEITÃO; COSTA, 2005; CHEVALIER, 2004) .

No presente estudo, os sites parecem entrecruzar os discursos midiáticos - traduzindo, à sua maneira, os discursos científicos - e os discursos publicitários, por estarem inseridos na lógica do mercado voltado para o emagrecimento. Partindo deste entrecruzamento, as estratégias de persuasão sugeriram diferir substancialmente das utilizadas pelos discursos médico-nutricionais calcados na busca da saúde e prevenção de doenças.

Embora os múltiplos discursos veiculados no mundo da dieta na Internet não se afastem dos discursos médico-nutricionais - a referência dieta hipocalórica e hipolipídica não parece ser contestada -, estes são reelaborados buscando elementos da vida cotidiana dos sujeitos para consubstanciá-los dentro da lógica publicitária. Há uma larga fluência de sentidos e significados nos recursos imagéticos dos corpos e da comida utilizados, nos discursos produzidos nos textos, nos relatos de experiência de sucesso, sempre focados no cotidiano dos sujeitos, produzindo identificações, projeções e desejos, como pôde ser observado na história de Ademaria.

Outro marco seria o paradoxo do sigilo e anonimato, com a produção de uma suposta proximidade e relação afetiva com os usuários. Isso mais uma 
vez nos faz refletir sobre o cenário da Internet e suas características ao lado das relações subjetivas que os sujeitos têm estabelecido com seus corpos e o excesso de peso. Por consequiência, os aspectos psicológicos e motivacionais ganham importância nesses sites.

No que tange ao discurso em torno das práticas alimentares para o emagrecimento, observaram-se tentativas de criar estratégias educacionais que transitem da concepção do "fazer dieta" para o conceito de reeducação alimentar concebida como "o comer de tudo sem passar fome". A gastronomia é o elo importante do resgate do prazer em comer, ao estabelecer uma aliança com as ciências da nutrição. Essa transição propõe uma ressignificação do comer e da comida e de novos sentidos dessa prática na vida dos sujeitos que, ainda que permeada pelo discurso publicitário e mercadológico, pode ser vista como importante estratégia de persuasão.

Por fim, cabe destacar a importância de estudar tais estratégias, pois esses programas de emagrecimento têm atraído um número significativo de participantes, embora não se tenha clareza de sua magnitude, tendo em vista que o emagrecimento tem sido uma meta desejada por grande parte da população, seja para melhorar a saúde, seja com fins estéticos.

\section{Referências}

ARNAIZ, M. G. Paradojas de la alimentación contemporánea, Barcelona: Icaria, 1996.

CASTRO, A. L. Culto ao corpo e sociedade. Mídia, estilos de vida e cultura de consumo, São Paulo: Annablume, 2003.

CHEVALIER, S. The internet: an ethnographic. Horizontes Antropológicos, Porto Alegre, ano 10, n. 21, p. 315-319, jan./jun. 2004.

FISCHLER, C. L'Homnivore. Paris: O. Jacob, 2001.

. O modelo alimentar mediterrâneo: mito e/ou realidade. Projeto História, São Paulo, n. 25, p. 23-35, dez. 2002.

FREITAS, M. C. S. Mulher light: corpo, dieta e repressão. In: FERREIRA, S. L; NASCIMENTO, E. R. (Org.). Imagens da mulher contemporânea. Salvador: UFBA, 2002. p. 23-34.

GIDDENS, A. Modernidade e identidade pessoal. Lisboa: Celta, 2001. 
LEITÃO, C. F.; COSTA, A. M .N. Impactos da internet sobre pacientes: a visão de psicoterapeutas. Psicologia em Estudo, Maringá, v. 10, n. 3, p. 441450, set./dez. 2005.

LIPOVETSKY, G. A terceira mulher. Permanência e revolução do feminino. São Paulo: Companhia das Letras, 2000.

LUPTON, D. Food, body and the self. London: Sage, 1996.

MIRA, M. C. O leitor e a banca de revistas: a segmentação da cultura no século XX. São Paulo: Olho d'Água, 2001.

POULAIN, J.-P. Sociologies de l'alimentation: les mangeurs l'espace social alimentaire, Paris: Presses Universitaires de France, 2003.

SANT'ANNA, D. B. Corpos de passagem. São Paulo: Estação Liberdade, 2001.

SANTOS, L. A. S. O corpo, o comer e a comida: um estudo sobre as práticas corporais e alimentares cotidianas a partir da cidade de Salvador-Bahia, São Paulo. Tese (Doutorado em Ciências Sociais)-Pontifícia Universidade Católica de São Paulo, São Paulo, 2006.

TURNER, B. The body and society: explorations in social theory. Oxford: B. Blackwell, 1984.

\section{NOTAS}

- Professora adjunta no Departamento Ciências da Nutrição, Escola de Nutrição, Universidade Federal da Bahia; mestre em Educação dos Profissionais de Saúde, University of Dundee, Escócia; doutora em Ciências Sociais, PUC-SP. Endereço eletrônico: amparo@ufba.br.

${ }^{1}$ Foram estudados, basicamente, os sites brasileiros mais conhecidos e utilizados, a saber: "Cyberdiet", "Emagrecendo", "Perca gordura”, "Sempre em Forma”, "Good Light” e "Dieta Diet". 


\section{Diet Programs on the Internet: brief notes}

This paper aims to describe and analyze some elements of diet programs offered on the Internet. The study observed that strategies used by the programs are familiar to people, and that psychological and motivational aspects are important. Therefore, there is an attempt to create educational strategies ranging from the concept of "doing diet" to "nutritional reeducation". The latter is understood as "to eat everything, without starving". This fact unveils an alliance between the nutritional sciences and gastronomy, which greatly helps recovering the pleasure of eating. The text points out the importance of studying such strategies, mainly because losing weight is the objective of the largest part of the population, either for improving health or for aesthetical purposes.

Key words: diet; diet programs; nutrition; Internet. 